\title{
ANALYSIS OF THE INCIDENCE OF PRIMARY BREAST CANCER IN RELATION TO THE TOTAL CASES IN THE FEMALE POPULATION OF THE CENTRAL-WEST SCENARIO
}

Paula O. C. Queiroz¹, Nayara P. A. Oliveira1, Hygor A. P. Dutra1, Thaynara P.1

${ }^{1}$ Universidade Federal de Goiás - Goiânia (GO), Brazil.

Objective: Compare the incidence of primary breast cancer in relation to the total cases in the female population of the Central-West scenario and capitals, except Federal District. Methodology: Cancer Incidence Estimates for the biennium 2018-2019 produced by the Division of Surveillance and Situation Analysis of the Coordination of Prevention and Surveillance (Conprev) of INCA / MS were used. Results: According to INCA data, breast cancer will account for 19.24\% of all cancer cases expected in Brazil in 2018 and 2019. For the Center-West region, this percentage is estimated to be $29 \%$. The state in which breast cancer has a higher incidence compared to the other neoplasms is Mato Grosso do Sul (60.90\%), in which the capital (Campo Grande) reaches $81.05 \%$. Goiás presents the second highest percentage (48.68\%), being in the capital Goiânia 72.17\%. Finally, in Mato Grosso, the lowest value is expected (41.32\%) and in its capital (Cuiabá), 59.03\%. Conclusion: Regional disparities in access to early detection of breast cancer could explain a higher or lower incidence of breast cancer in the different states that make up the Central-West. It is known that, with the increase of the access by the population to mammography, the incidence of breast cancer tends to increase, reflecting greater access to early diagnosis. In this sense, a lower mortality rate can be expected in these regions, due to an early diagnosis. 